European Psychiatry

www.cambridge.org/epa

\section{Research Article}

Cite this article: Mollon J, Knowles EEM, Mathias SR, Rodrigue A, Moore TM, Calkins ME, Gur RC, Peralta JM, Weiner DJ, Robinson EB, Gur RE, Blangero J, Almasy L, Glahn DC (2021). Genetic influences on externalizing psychopathology overlap with cognitive functioning and show developmental variation. European Psychiatry, 64(1), e29, 1-9 https://doi.org/10.1192/j.eurpsy.2021.21

Received: 15 January 2021

Revised: 17 March 2021

Accepted: 18 March 2021

\section{Keywords:}

Cognition; development; externalizing;

Gene $\times$ Age; heritability; pleiotropy;

psychopathology

\section{Author for correspondence:}

* Josephine Mollon,

E-mail: josephine.mollon@childrens.harvard. edu

\title{
Genetic influences on externalizing psychopathology overlap with cognitive functioning and show developmental variation
}

\author{
Josephine Mollon $^{1 *}$ (1), Emma E. M. Knowles ${ }^{1}$, Samuel R. Mathias ${ }^{1}$, \\ Amanda Rodrigue $^{1}$, Tyler M. Moore ${ }^{2}$ (D) Monica E. Calkins ${ }^{2}$, Ruben C. Gur ${ }^{2}$, \\ Juan Manuel Peralta ${ }^{3}$, Daniel J. Weiner ${ }^{4,5,6}$ (D) Elise B. Robinson ${ }^{4,5,6}$, Raquel E. Gur ${ }^{2}$, \\ John Blangero ${ }^{3}$, Laura Almasy ${ }^{7}$ and David C. Glahn ${ }^{1,8}$
}

${ }^{1}$ Department of Psychiatry, Boston Children's Hospital, Harvard Medical School, Boston, Massachusetts, USA; ${ }^{2}$ Brain Behavior Laboratory, Department of Psychiatry, Perelman School of Medicine, Penn-CHOP Lifespan Brain Institute, University of Pennsylvania, Philadelphia, Pennsylvania, USA; ${ }^{3}$ South Texas Diabetes and Obesity Institute, School of Medicine, University of Texas of the Rio Grande Valley, Brownsville, Texas, USA; ${ }^{4}$ Analytic and Translational Genetics Unit, Department of Medicine, Massachusetts General Hospital and Harvard Medical School, Boston, Massachusetts, USA; ${ }^{5}$ Stanley Center for Psychiatric Research, Broad Institute of MIT and Harvard, Cambridge, Massachusetts, USA; ${ }^{6}$ Program in Medical and Population Genetics, Broad Institute of MIT and Harvard, Cambridge, Massachusetts, USA; ${ }^{7}$ Department of Genetics, Perelman School of Medicine, Penn-CHOP Lifespan Brain Institute, University of Pennsylvania, Philadelphia, Pennsylvania, USA and ${ }^{8}$ Olin Neuropsychiatry Research Center, Institute of Living, Hartford, Connecticut, USA

\begin{abstract}
Background. Questions remain regarding whether genetic influences on early life psychopathology overlap with cognition and show developmental variation.

Methods. Using data from 9,421 individuals aged 8-21 from the Philadelphia Neurodevelopmental Cohort, factors of psychopathology were generated using a bifactor model of item-level data from a psychiatric interview. Five orthogonal factors were generated: anxious-misery (mood and anxiety), externalizing (attention deficit hyperactivity and conduct disorder), fear (phobias), psychosis-spectrum, and a general factor. Genetic analyses were conducted on a subsample of 4,662 individuals of European American ancestry. A genetic relatedness matrix was used to estimate heritability of these factors, and genetic correlations with executive function, episodic memory, complex reasoning, social cognition, motor speed, and general cognitive ability. Gene $\times$ Age analyses determined whether genetic influences on these factors show developmental variation.

Results. Externalizing was heritable $\left(h^{2}=0.46, p=1 \times 10^{-6}\right)$, but not anxious-misery $\left(h^{2}=0.09\right.$, $p=0.183)$, fear $\left(h^{2}=0.04, p=0.337\right)$, psychosis-spectrum $\left(h^{2}=0.00, p=0.494\right)$, or general psychopathology $\left(h^{2}=0.21, p=0.040\right)$. Externalizing showed genetic overlap with face memory $\left(\rho_{g}=-0.412, p=0.004\right)$, verbal reasoning $\left(\rho_{g}=-0.485, p=0.001\right)$, spatial reasoning $\left(\rho_{g}=-0.426\right.$, $p=0.010)$, motor speed $\left(\rho_{g}=0.659, p=1 \times 10^{-4}\right)$, verbal knowledge $\left(\rho_{g}=-0.314, p=0.002\right)$, and general cognitive ability $(g)\left(\rho_{g}=-0.394, p=0.002\right)$. Gene $\times$ Age analyses revealed decreasing genetic variance $\left(\gamma_{g}=-0.146, p=0.004\right)$ and increasing environmental variance $\left(\gamma_{e}=0.059\right.$, $p=0.009)$ on externalizing.

Conclusions. Cognitive impairment may be a useful endophenotype of externalizing psychopathology and, therefore, help elucidate its pathophysiological underpinnings. Decreasing genetic variance suggests that gene discovery efforts may be more fruitful in children than adolescents or young adults.
\end{abstract}

(c) The Author(s), 2021. Published by Cambridge University Press on behalf of the European Psychiatric Association. This is an Open Access article, distributed under the terms of the Creative Commons Attribution licence (http:// creativecommons.org/licenses/by/4.0/), which permits unrestricted re-use, distribution, and reproduction in any medium, provided the original work is properly cited.

EUROPEAN PSYCHIATRIC ASSOCIATION

\section{Introduction}

Psychiatric symptoms in early life are associated with poor cognition [1]. For example, psychotic symptoms in childhood and adolescence are associated with cognitive impairment $[2,3]$. There is also evidence for IQ deficits in children with conduct problems [4], vocabulary deficits in children with aggression [5], visuospatial deficits in children with hyperactivity [6], and social deficits in adolescents with externalizing problems [7]. Small, generalized deficits have also been reported in children with symptoms of anxiety and depression [8].

Early life psychopathology is also underpinned by genes with evidence of substantial genetic effects on childhood and adolescent psychopathology [9,10], as well as specific psychotic [11,12], externalizing [13-15], internalizing [16], and anxiety/depression symptoms [17-21]. Since cognition in early life is also influenced by genes [22,23], recent studies have examined whether there is a genetic component to cognitive correlates of early life psychopathology. Evidence from 
twin and family studies shows genetic overlap between psychopathology and cognitive ability [24], psychopathology and executive functions [25], attention deficit hyperactivity disorder (ADHD) and IQ [26], ADHD and executive functions [27,28], and inattention and attention regulation [29]. GWAS evidence shows genetic overlap between ADHD and intelligence [30-32], academic underperformance [31,33,34], and executive functions [35]. However, a comprehensive examination of genetic underpinnings of cognitive impairment in early life psychopathology, that is, comprising multiple dimensions of psychopathology and cognition, is lacking.

Gaps in knowledge also exist regarding whether genetic influences on early life psychopathology show developmental variation. A recent review reported static and dynamic effects on internalizing and externalizing symptoms between infancy and early adulthood [13], with certain genetic effects remaining influential throughout development, and novel genetic factors also emerging. However, previous studies focused on developmental periods rather than examining age continuously. Another way to test for developmental variation in genetic influences is Gene $\times$ Age $(G \times A)$ interactions. $\mathrm{G} \times \mathrm{A}$ interactions can be tested using a cross-sectional design that models differences in psychopathology as a function of relatedness and similarity in age between individuals [36-38]. Thus, $\mathrm{G} \times \mathrm{A}$ analysis tests for fluctuations in action of genetic factors, as well as variation in genetic factors at different ages [23].

We used data from the Philadelphia Neurodevelopmental Cohort (PNC) [1], a large population-based sample aged 8-21, to derive factors of psychopathology using a bifactor model of item-level data from a psychiatric interview $[39,40]$. In bifactor models, items load on two factors simultaneously: (a) a general factor that accounts for commonality of all items (here general psychopathology) and (b) specific factors that account for unique influence of specific domains over and above the general factor (specific dimensions of psychopathology) [41,42]. Thus, bifactor models estimate the contribution of items to the general factor after controlling for specific factors, and vice versa [39]. Therefore, the utility of bifactor models lies in their ability to parse out this shared variance between general and specific factors, such that there is no contamination between factors, meaning that the general factor cannot account for findings in the specific factors, or vice versa. In other words, bifactor models allow examination of the unique contribution of the general and specific factors to prediction of external factors, or of the unique contribution of external factors (here genetic factors) to the general and specific factors $[43,44]$. Importantly, bifactor models accommodate orthogonal factor scores despite correlated latent factors [39,43]. We then used a genetic relatedness matrix to establish whether these psychopathology factors (a) were heritable, (b) showed genetic overlap with cognition, and (b) showed $\mathrm{G} \times \mathrm{A}$ interactions. In line with previous evidence, we hypothesized that psychopathology factors, would be (a) heritable, (b) show negative genetic correlations with cognitive functioning, and (c) be influenced by developmentally dynamic genetic factors, that is, show $\mathrm{G} \times \mathrm{A}$ interactions.

\section{Methods \\ Participants}

PNC is a population-based sample from the greater Philadelphia area, comprising 9,421 individuals aged 8-21. The study has been described in detail [1]. Briefly, between 2006 and 2012, 50,293 adults were recruited by the Center for Applied Genomics at Children's Hospital of Philadelphia and provided access to Electronic Medical Records (EMRs). EMRs were screened for eligibility for PNC participation, yielding 19,161 individuals, released to the recruitment team in weekly waves between 2009 and 2011. Potential probands (ages 18-21) or caregivers/legal guardians (ages 8-17) were sent letters introducing the study, and then contacted by phone to explain the study, verify eligibility, and schedule appointments. Participants provided written consent for genomic studies upon providing blood samples during the clinical visit. Inclusion criteria were: (a) ability to provide signed informed consent (parental consent for participants <18), (b) English language proficiency, and (c) physical and cognitive ability to participate in cognitive testing. Data are in dbGaP (https://www.ncbi.nlm.nih.gov/projects/gap/cgibin/study.cgi?study_id=phs000607.v3.p2).

Genetic analyses were limited to participants who identified as white non-Hispanic (European American), leaving 4,662 subjects with genetic, cognitive, and psychiatric data. Mean age was 13.8 (standard deviation $[\mathrm{SD}]=3.6), 50.3 \%$ were male $(n=2,346)$.

\section{Cognitive assessment}

Participants completed the Penn computerized neurocognitive battery $[45,46]$, which consists of 14 tests that capture functioning in five domains: (a) executive function (abstraction and mental flexibility, attention, working memory), (b) episodic memory (verbal, facial, spatial), (c) complex cognition (verbal reasoning, nonverbal reasoning, spatial processing), (d) social cognition (emotion identification, emotion differentiation, age differentiation), and (e) speed (motor, sensorimotor). Accuracy and reaction times are recorded for each test. All tests show moderate to very high reliability [47]. The battery also included the reading subtest of the Wide Range Achievement Test (WRAT), a measure of general verbal knowledge. As in our prior work [23], we derived a general composite score $(g)$ as the first component of principal component analysis (PCA) of accuracy scores. We also derived a general composite score for speed $(g s)$ as the first component of PCA of reaction times. To minimize the impact of missing data, multivariate imputation by chained equation (MICE) [48] was used to impute missing values using the mice package in $\mathrm{R}$ [49]. Imputation was based on age, sex and available cognitive data (participants missing $<50 \%$ cognitive data) [23]. Subsequent analyses were conducted on imputed data.

\section{Psychopathology assessment}

Psychiatric symptoms were ascertained using a computerized, structured interview (GOASSESS) [1,39,50], a modified version of the Kiddie-Schedule for Affective Disorders and Schizophrenia [51]. GOASSESS was administered to caregivers/legal guardians (ages 8-10), participants and caregivers/legal guardians (ages 11-17), and participants (ages 18-21). Bachelor- and Master-level assessors underwent a 25 -h training protocol comprising didactic sessions, assigned readings, and supervised pairwise practice. Assessors were certified through standardized procedures requiring observation by a certified clinical observer who rated proficiency on a 60 -item checklist of interview procedures. Responses coded by the assessor were required to correspond to responses coded by a certified clinical observer. Assessors underwent repeat observation until meeting passing criteria [1].

\section{Factor analysis to create factors of psychopathology}

We applied a confirmatory bifactor model [43] in Mplus [52] to 112 items from the GOASSESS [1,39,40](Figure 1a) using mean- and variance-adjusted weighted least squared estimator. Five 

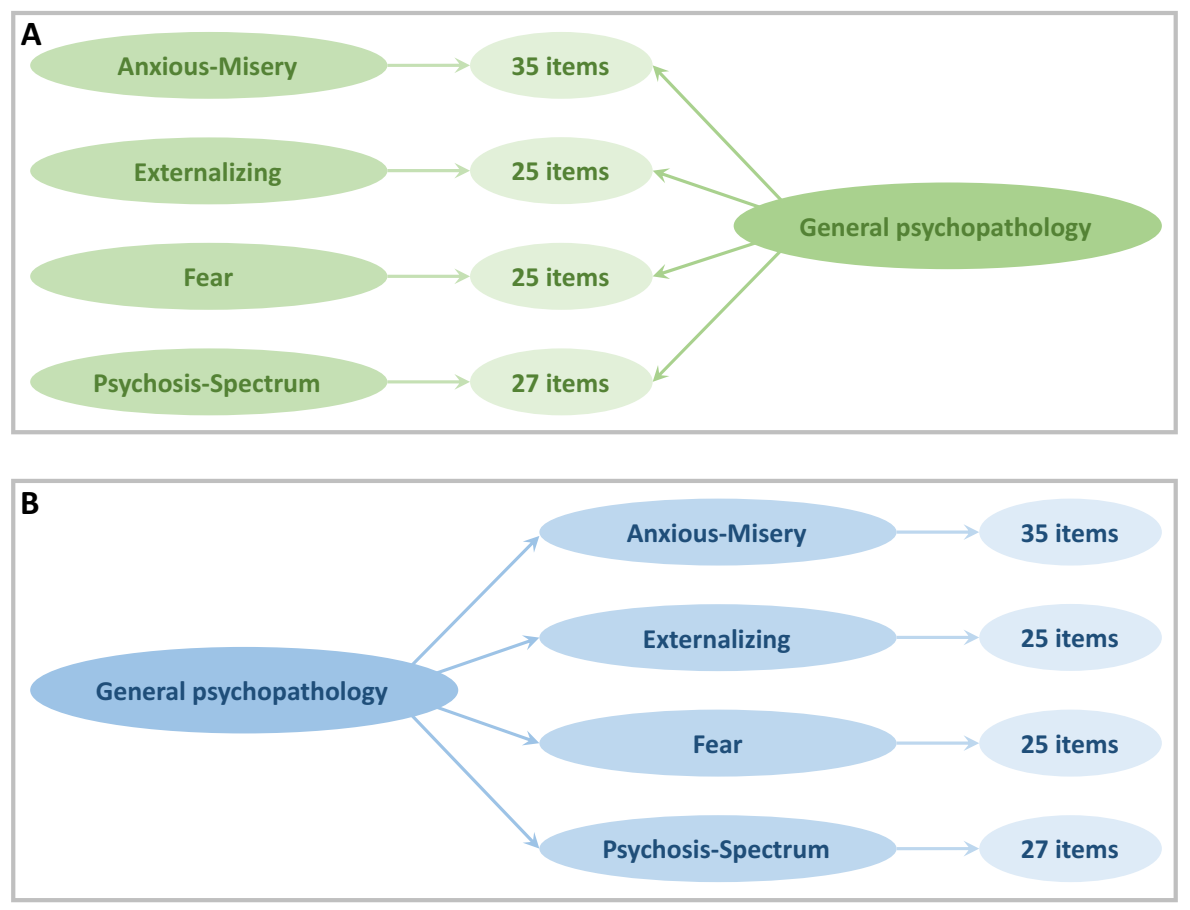

Figure 1. Schematic of (a) bifactor and (b) hierarchical models of 112 items from the GOASSESS structured interview.

orthogonal factors of psychopathology were generated for 9,421 individuals with GOASSESS data: (a) anxious-misery (mood and anxiety), (b) externalizing (ADHD and conduct disorder), (c) fear (phobias), (d) psychosis-spectrum, and (e) a general factor of overall psychopathology. Since bifactor models estimate the contribution of items to an overall dimension (general psychopathology) after controlling for specific factors, and vice versa, all factors (both general and specific) are orthogonal. Thus, bifactor models parse out the shared variance between general and specific factors, such that there is no contamination between factors. Therefore, bifactor models allow examination of the unique contribution of external factors (here genetic factors) to the general and specific factors [43,44]. Table S1 shows factor loadings, Table S2 shows correlations between factors (and with cognition), Figure S1 shows test information plots.

\section{Genotyping}

Samples were genotyped on one of four Illumina arrays: HumanHap550, HumanHap610, OmniExpress, or Human1M. Genotyped data were imputed at the Broad Institute [53] using IMPUTE2 and reference haplotypes in Phase I of the 1000 genomes data (June 2011 release) that included $\sim 37,138,905$ variants from 1,094 individuals from Africa, Asia, Europe, and the United States. Imputed genotype data were used in subsequent analyses.

\section{Estimation of genetic relatedness matrix}

Empirical relatedness quantifies the proportion of alleles that are identical by descent between individuals. Empirical relatedness was calculated for all pairs of individuals using genotype data [23]. Briefly, $50 \mathrm{k}$ common autosomal single nucleotide proteins (SNPs) in approximate linkage equilibrium were selected from all available SNP variants after linkage disequilibrium (LD) pruning $\left(r^{2}>0.1\right)$ using PLINK [54]. Relatedness was estimated from these SNPs using IBDLD [55](up to 50 SNPs within a $2-\mathrm{cm}$ span). The matrix was inspected to ensure correct properties (trace equal to number of genotyped subjects, symmetry, positive semi-definiteness, range of diagonal, and off-diagonal elements). Distribution of estimated relatedness values has been presented previously [23]. Empirical genetic relatedness matrices are advantageous because quantitative genetic analyses (described below) that are traditionally applied to family data using genetic relatedness matrices calculated from pedigree information can, in turn, be applied to cohorts of related and/or unrelated individuals (such as the PNC) using empirical genetic relatedness instead.

\section{Statistical and quantitative genetic analyses}

$\mathrm{R}$ [56] was used to generate descriptive statistics and graphics. Genetic analyses were conducted in Sequential Oligogenetic Linkage Analysis Routines (SOLAR) [57] on 4,662 participants who identified as white non-Hispanic (European American), regardless of relatedness. While analyses in SOLAR performed on family data are robust to population stratification, the PNC sample comprises both related and unrelated individuals. Therefore, we only included individuals of European American ancestry (the most common ancestry group in the PNC sample) in our analyses and excluded individuals of non-European ancestry. Relatedly, since rare variants that may explain a substantial proportion of phenotypic variance are not well captured by common SNPs, using related individuals is more powerful than using unrelated individuals when estimating heritability, but the combination of related and unrelated individuals, as in the PNC, is optimal. Moreover, related individuals (even distantly) are critical for detecting $\mathrm{G} \times \mathrm{A}$ interactions (described below). When using only unrelated individuals it is not possible to detect changes in genetic correlation over time since related pairs serve as a pseudo-longitudinal design where the same polygenotypes are observed at different ages.

\section{Univariate and bivariate polygenic models}

SOLAR implements linear mixed-effects models, which decompose the overall variance of a quantitative trait $[58,59]$. Traditionally, 
Josephine Mollon et al.

these analyses are performed on family data using matrices calculated from pedigree information, but can be applied to cohorts of related and unrelated individuals using relatedness estimated from genotype data [60]. Under a univariate polygenic model, the phenotypic variance $\left(\sigma_{p}^{2}\right)$ of a trait is decomposed into genetic $\left(\sigma_{g}^{2}\right)$ and environmental $\left(\sigma_{e}^{2}\right)$ components. Environmental variance incapsulates all variance that is not genetic, including error. Narrowsense heritability $\left(h^{2}\right)$ is the proportion of phenotypic variance accounted for by additive genetic variance $\left(h^{2}=\sigma_{g}^{2} / \sigma_{p}^{2}\right)$. To determine whether heritability $\left(h^{2}\right)$ was significantly greater than 0 , likelihood of the polygenic model was compared to that of a model with $h^{2}$ constrained to 0 . Under a bivariate polygenic model, phenotypic covariance between two traits is decomposed into genetic and environmental components to determine the extent to which traits are influenced by shared genetic effects. Since genetic correlations between traits are only meaningful if traits are heritable, we estimated heritability of all traits. Bivariate polygenic analyses were then applied to significantly heritable pairs of traits to estimate genetic $\left(\rho_{g}\right)$, environmental $\left(\rho_{e}\right)$, and phenotypic $\left(\rho_{p}\right)$ correlations. The genetic correlation $\left(\rho_{g}\right)$ denotes the correlation between latent additive genetic factors influencing both traits. The environmental correlation $\left(\rho_{e}\right)$ denotes the correlation between nongenetic factors influencing both traits. To determine whether genetic $\left(\rho_{g}\right)$ and environmental $\left(\rho_{e}\right)$ correlations were significantly different from 0 , likelihood of the bivariate polygenic model was compared to that of a model where the parameter of interest was constrained to 0 .

\section{Gene $\times$ Age interaction models}

A polygenic model can be extended to examine Gene $\times$ Environment $(G \times E)$ interactions [36-38]. One consequence of $G \times E$ is that additive genetic variance is greater under certain environments than others. To test for this effect with a continuous environmental variable (age), the polygenic model is modified to include a linear function on the logarithm of $\sigma_{g}^{2}$. This linear function contains a free parameter, $\gamma$, reflecting change in $\sigma_{g}^{2}$ unit of the environmental variable (age in years). A nonzero value of $\gamma$ implies a heritable response to the environment, and therefore, a $\mathrm{G} \times \mathrm{E}$ interaction. This $\mathrm{G} \times \mathrm{E}$ interaction tests for fluctuations (with age) in action of genetic factors and a significant $\mathrm{G} \times \mathrm{E}$ interaction suggests a change in magnitude of effect of specific genetic factors (with age). A second consequence of $\mathrm{G} \times \mathrm{E}$ is that the trait exhibits imperfect pleiotropy with itself, that is, the genetic correlation between the trait measured under one environment and the trait measured under another environment is less than 1 . This phenomenon can be examined in cross-sectional studies where individuals are tested under a single environment (timepoint), provided relatedness between individuals is known [37]. To test for this effect, the polygenic model is modified to include another free parameter, $\lambda$, reflecting the rate of decay in genetic correlation $\left(\rho_{g}\right)$ as difference in the environmental variable increases. A nonzero value of $\lambda$ implies imperfect pleiotropy, and therefore, a $\mathrm{G} \times \mathrm{E}$ interaction. This $\mathrm{G} \times \mathrm{E}$ interaction tests for variation in genetic factors influencing the trait (at different ages) and a significant $\mathrm{G} \times \mathrm{E}$ interaction suggests a change (with age) in the genetic factors themselves. $\mathrm{G} \times \mathrm{E}$ interaction models were fitted to heritable traits, with age in years as the continuous environmental variable that is, Gene $\times$ Age interactions. See Table S3 for more information.

All models included age, age ${ }^{2}$, sex, and their interactions as covariates. To adjust for multiple testing, false discovery rate (FDR) was set at 5\% [61]. Rank-based inverse normal transformations were applied to all traits to ensure normality.

\section{Sensitivity analyses}

In addition to the bifactor model described above, we applied a confirmatory hierarchical model (Figure 1b) in Mplus [52] to generate four correlated factors of psychopathology and a general factor. We generated the same factors as the bifactor model: specific factors of (a) anxious-misery, (b) externalizing, (c) fear, and (d) psychosis-spectrum, and (e) a general factor. In bifactor models, general and specific factors are orthogonal, whereas in hierarchical models, the general factor is defined by the specific factors and thus general and specific factors are explicitly correlated. Univariate, bivariate, and $\mathrm{G} \times \mathrm{A}$ analyses, as described above, were repeated on these factors to examine the contaminating effect, that is shared variance of general and specific factors. Table S4 shows factor loadings, Table S5 shows correlations between factors (and with cognition), Figure S2 shows test information plots.

\section{Results}

\section{Externalizing psychopathology is heritable}

Significant heritability estimates were observed for general $\left(h^{2}=0.21\right.$, $p=0.040)$ and externalizing psychopathology $\left(h^{2}=0.46\right.$, $\left.p=2 \times 10^{-6}\right)$, but only externalizing survived FDR correction (Figure 2 and Table 1). As reported previously [23], most accuracy $\left(h^{2}\right.$ range $\left.=0.21-0.72\right)$ and reaction time $\left(h^{2}\right.$ range $\left.=0.23-0.38\right)$ measures were also heritable. Subsequent bivariate and $\mathrm{G} \times \mathrm{A}$ analyses were run on significantly heritable traits (after FDR correction).

\section{Overlapping genetic factors on externalizing and cognition suggest pleiotropic effects}

Externalizing showed significant negative phenotypic correlations with most accuracy measures (range $\rho_{p}=-0.042$ to -0.127 ) and some reaction time measures (range $\rho_{p}=-0.036$ to -0.66 ; Table 1 ) after FDR correction, such that greater psychopathology was associated with poorer accuracy and slower reaction times. Significant negative genetic correlations were observed after FDR correction between externalizing and accuracy measures of face memory $\left(\rho_{g}=-0.412, p=0.004\right)$, verbal reasoning $\left(\rho_{g}=-0.485\right.$, $p=0.001)$, spatial processing $\left(\rho_{g}=-0.426, p=0.010\right)$, general verbal knowledge $\left(\rho_{g}=-0.314, p=0.002\right), g\left(\rho_{g}=-0.44, p=0.002\right)$, and sensorimotor speed $\left(\rho_{g}=-0.659, p=1 \times 10^{-4}\right)$ suggesting that genetic factors underlying externalizing overlap with lower accuracy and slower reaction times.

\section{Genetic variance on externalizing decreases with age}

Significant decrease in genetic variance was observed on externalizing $\left(\gamma_{g}=-0.146, p=0.004\right.$; Figure 3$)$, suggesting that specific genetic factors influence externalizing psychopathology between childhood and early adulthood, but also that the magnitude of effect of these genetic factors decreases with age. Significant increase in environmental variance was also observed $\left(\gamma_{e}=0.059, p=0.009\right)$. Decay in genetic correlation did not reach statistical significance $(\lambda=0.027, p=0.423)$, such that we did not find evidence for change in genetic factors, that is, novel genetic influences. Data presented in Figure 3 were generated using Formula 5 in Table S3.

\section{Results of genetic analyses are robust to factor analytic approach}

Univariate, bivariate, and $\mathrm{G} \times \mathrm{A}$ analyses conducted on psychopathology factors derived from the hierarchical model generated 


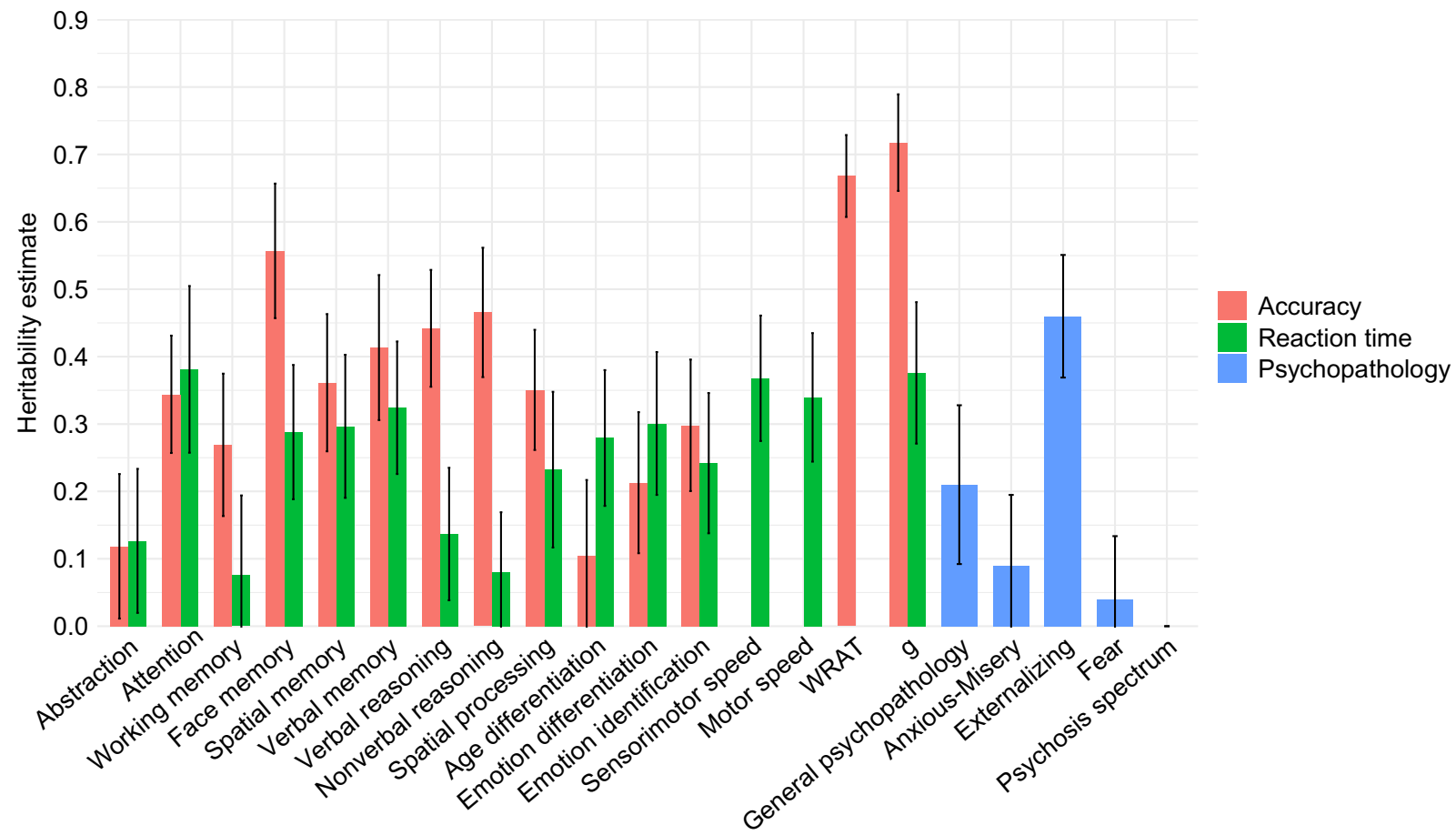

Figure 2. Heritability estimates for all neurocognitive measures and psychopathology factors. *Error bars represent standard errors (SEs).

similar results. Externalizing $\left(h^{2}=0.58, p=1 \times 10^{-7}\right)$ remained heritable, but general psychopathology $\left(h^{2}=0.37, p=0.001\right)$ anxious-misery $\left(h^{2}=0.35, p=0.002\right)$ and fear $\left(h^{2}=0.25\right.$, $p=0.011)$ were also significantly heritable, although fear did not survive FDR correction (Table S6 and Figure S3). General psychopathology and anxious-misery showed significant phenotypic correlations with cognition (Table S6), but only externalizing showed significant genetic correlations with verbal reasoning $\left(\rho_{g}=-0.43\right.$, $p=0.001)$, general verbal knowledge $\left(\rho_{g}=-0.25, p=0.005\right)$, and $g$ $\left(\rho_{g}=-0.37, p=3 \times 10^{-6}\right)$, after FDR correction. Again, significant decrease in genetic variance $\left(\gamma_{g}=-0.112, p=0.029\right)$ and increase in environmental variance $\left(\gamma_{e}=0.089, p=0.008\right)$ were observed for externalizing (Figure S4) Change in genetic variance on general psychopathology $\left(\gamma_{g}=0.017, p=0.279\right)$ and anxious-misery $\left(\gamma_{g}=0.023, p=0.269\right)$ was not significant. Data presented in Figure S4 were generated using Formula 5 in Table S3.

\section{Discussion}

Using a large, population-based cohort of individuals aged 8-21, we showed that externalizing psychopathology in the first two decades of life is under considerable genetic influence. Externalizing showed genetic overlap with lower performance on face memory, verbal reasoning, spatial processing, motor speed, verbal knowledge, and general cognitive ability. We did not find evidence for novel genetic factors on externalizing throughout this developmental period, rather we found a decrease in genetic variance, and increase in environmental variance. These findings have several implications for our understanding of early life psychopathology.

First, to the best of our knowledge, this is the first study to use a large, population-based cohort and genetic relatedness matrix to estimate heritability of data-driven factors of psychopathology (both orthogonal and correlated) throughout childhood and early adulthood. Our finding of heritable general psychopathology, anxious-misery, externalizing, and fear are in line with previous evidence [11-15]. We did not find evidence for genetic influences on the psychosis-spectrum factor, in contrast to prior evidence $[11,12]$. However, SNP heritability estimates of psychotic symptoms are more modest, with a report of nonsignificant and zero estimates for paranoia and hallucinations, respectively [62]. Moreover, while there has been progress in delineating molecular genetic underpinnings of adult schizophrenia [63], the same cannot be said of childhood psychotic symptoms [64]. Notably, subjects were less likely to endorse items that loaded on the psychosis-spectrum factor (average $11 \%$ endorsing), than on externalizing (21\%), anxious-misery (15\%), and fear (16\%). Similarly, clinical diagnostic rates of attention deficit, oppositional defiant, and conduct disorders in PNC are 16, 33, and 7\%, respectively [40], while rate of threshold psychotic symptoms is $4 \%$ [65]. Psychotic symptoms also emerge later during development than symptoms relating to externalizing, anxious-misery, and fear [66,67].

In contrast, we found externalizing psychopathology to be significantly and moderately heritable, with genetic factors explaining $46-58 \%$ of the variance. Equally substantial genetic influences on externalizing between ages 8 and 26 have been reported in twin and adoption studies [13-15]. A very similar SNP heritability of 0.44 has also been reported for externalizing [68], but another study found SNP heritability estimates of zero for a range of externalizing problems [69]. Differences between SNP and pedigree heritability estimates are likely due to rare variants not well captured by common SNPs, with SNP heritability representing the lower bound. Thus, using related individuals is more powerful than using unrelated individuals when estimating heritability, and the combination of all possible relationships, as in our sample, results in something of a hybrid between SNP and pedigree estimates. However, shared environment may contribute to heritability inflation when using related individuals. Nevertheless, rare variants account for a significant proportion of total heritability [70], and our heritability estimates are generally in line with previous studies. 
Table 1. Heritability estimates for all traits, genetic, and phenotypic correlations between externalizing and cognition.

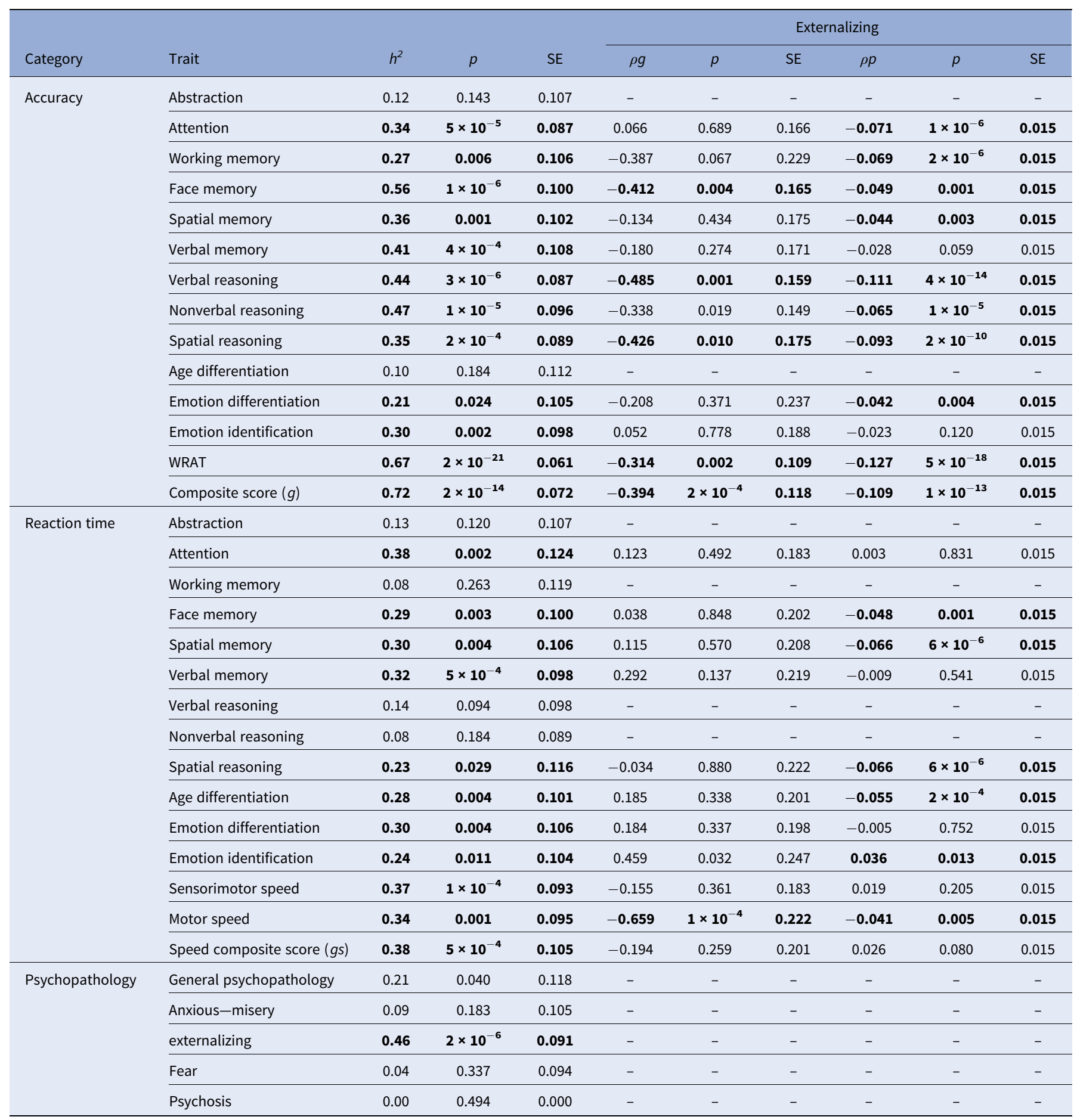

Bolded estimates significant after correction for multiple testing (FDR $=0.05)$.

Abbreviations: AWRAT, Wide Range Achievement Test; SE, standard error.

Importantly, we found significant heritability estimates for general psychopathology and anxious-misery factors generated from a hierarchical, but not bifactor, model. This finding highlights the utility of bifactor models, in which all factors (both general and specific) are orthogonal $[40,71]$, thereby allowing us to examine the unique contribution of genetic factors to general psychopathology and specific factors of anxious-misery, externalizing, fear, and psychosis-spectrum $[43,44]$. This finding, as well as the finding of stronger genetic influences on externalizing than general psychopathology, is also in line with previous evidence of genetic signal on specific cognitive factors emerging only when variance associated with general cognitive ability is parsed out, that is when applying a bifactor model [71]. In hierarchical models, on the other hand, variance associated with the general factor may account for significant findings in the specific factors, and vice versa. Thus, our findings suggest that genetic effects underlying early-life anxiety 


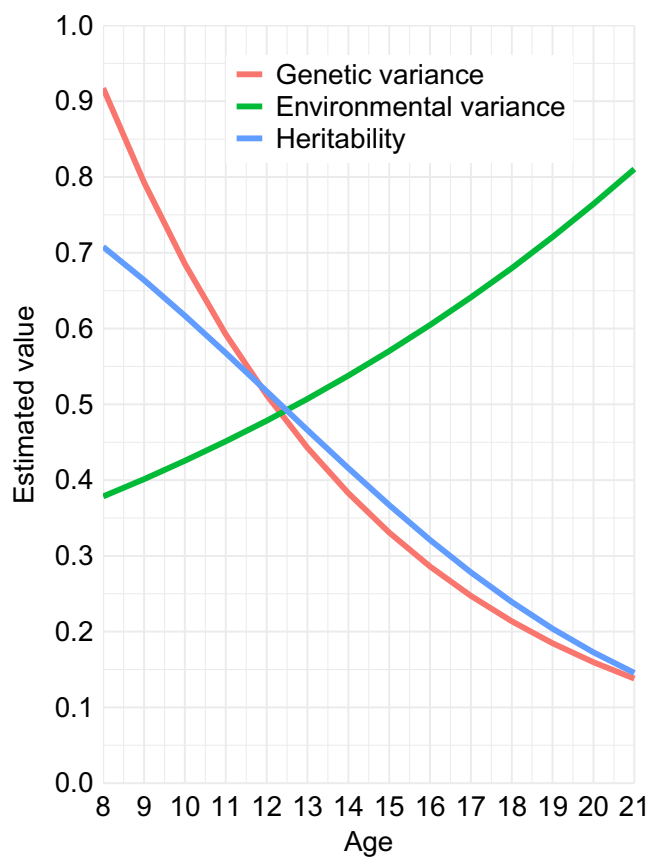

Figure 3. Estimated genetic variance, environmental variance and heritability by age for externalizing.

and depression may underlie more general psychopathology. Estimates of genetic influence on childhood anxiety [17,18], depression $[19,20]$, and phobias [72,73] are heterogeneous, ranging from small to large $\left(h^{2}=0.15-0.77\right)$ for anxiety and depression $[17,19]$, and for phobias $\left(h^{2}=0.23-0.72\right)[72,73]$.

Second, we found negative genetic correlations between externalizing and face memory, verbal reasoning, spatial processing, sensorimotor speed, verbal knowledge, and general cognitive ability $(g)$. These findings are in line with previous evidence of genetic overlap between ADHD and general and executive cognitive functions [27-32,35], but expand knowledge by showing that genetic overlap extends to externalizing psychopathology more generally, as well as to memory, complex reasoning, and speed functions. Similarly, in the same sample, genetic overlap was reported between inattention and memory, social cognition, executive function, and complex reasoning [74]. Genetic overlap between externalizing and cognitive functioning may be due to the same genetic factors influencing both traits. A recent genome-wide meta-analyses identified shared risk loci for ADHD and intelligence [31]. Rare genetic variants have also been identified for cognition [75,76] and ADHD [77], with overlapping genes implicated in ADHD studies of common and rare variants [78]. However, while there is evidence of common and rare variants disrupting similar biological pathways in ADHD [79], the neurobiological mechanisms underlying shared genetic influences on $\mathrm{ADHD}$ and intelligence remain unclear [31]. Future studies that utilize animal models are needed to elucidate the causal and biological pathways underlying these shared genetic influences. Alternatively, cognitive impairments may lead to externalizing, and/or vice versa. Importantly, different cognitive measures show different psychometric properties and associations with specific functions require replication. Future longitudinal studies incorporating behavioral, neuroimaging, and genetic data can further disentangle these associations. Nevertheless, our findings suggest that cognitive impairment may be a useful endophenotype $[80,81]$ of externalizing psychopathology. Interestingly, the WRAT, a measure of verbal knowledge showed the strongest phenotypic correlation with externalizing, but the weakest (statistically significant) genetic correlation. This finding highlights the importance of elucidating genetic underpinnings of phenotypic associations to delineate biological etiology.

Finally, we found static and dynamic genetic influences on externalizing psychopathology between childhood and early adulthood, in line with previous evidence [13-15,82]. While we did not find evidence for novel genetic influences, we found a decrease in genetic variance, and increase in environmental variance. Our findings are in line with those of Huizink [15], who found a decrease in genetic influences on externalizing from 43 to $29 \%$ between age 12 and 26, as well as an increase in environmental influences from 39 to $52 \%$ between these ages. Similarly, Wichers [14] found a decrease in genetic effects from 78 to $73 \%$ and an increase in environmental effects from 20 to $26 \%$ between age 8 and 20 , but also reported novel genetic influences throughout adolescence [14]. Huizink, on the other hand, reported novel environmental, but not genetic, influences [15]. Several phenomena may underlie these $\mathrm{G} \times \mathrm{A}$ interactions. Genes may become less expressed due to maturational processes involving hormonal and physical development [13]. Increasing environmental influences likely reflect growing peer influences and substance use [83]. Of note, environmental variance in this study incapsulates all variance that is not genetic. However, measurement error is unlikely to account for our findings since reliability of our factors is high (Figures S1 and S2). Moreover, method of symptom reporting differed by age, and genetic effects may differ by reporting method. For example, Scourfield et al. [84] found heritability estimates of 54 and 35\% for parent- and self-reported conduct problems, respectively. Nevertheless, $\mathrm{G} \times \mathrm{A}$ interaction analyses adjusting additionally for reporting method generated similar findings, with significant decrease in genetic variance $\left(\gamma_{g}=-0.151, p=0.002 ; \gamma_{g}=-0.112, p=0.026\right)$, and increase in environmental variance $\left(\gamma_{e}=0.058, p=0.006 ; \gamma_{e}=0.092\right.$, $p=0.007)$ on externalizing factors derived from bifactor and hierarchical models, respectively. Future studies that are able to combine longitudinal, self- and parent-report symptom data will help elucidate these age-associated effects further. Conversely, we previously reported increasing genetic and environmental variance on general cognitive ability in this sample [23]. Thus, while a proportion of genetic factors underlying externalizing and cognition overlap, other, nonoverlapping genetic influences may show diverging developmental trajectories. Advanced quantitative genetic methods may shed light on trajectories of shared genetic influences.

This study has limitations. First, our analyses were restricted to European American individuals and future studies should include other populations. Second, our data were cross-sectional and longitudinal studies with repeated assessments of identical measures and individuals are needed to fully establish age-related changes in genetic factors. Third, lower heritability estimates for general psychopathology and anxious-misery meant less power to detect genetic correlations with cognition and $\mathrm{G} \times \mathrm{A}$ interactions. Finally, although we used a large sample, and comprehensive assessments of cognition and psychopathology, our findings require replication.

Acknowledgment. The authors thank all study participants.

Conflicts of Interest. The authors declare no conflicts of interest.

Financial Support. This research was supported by National Institute of Mental Health grants R01 MH107248 and MH107235. 
Supplementary Materials. To view supplementary material for this article, please visit http://dx.doi.org/10.1192/j.eurpsy.2021.21.

Data Availability Statement. The data that support the findings of this study are openly available in the database of Genotypes and Phenotypes $(\mathrm{dbGaP})$ : https://www.ncbi.nlm.nih.gov/projects/gap/cgi-bin/study.cgi?study_ id=phs000607.v3.p2.

\section{References}

[1] Calkins ME, Merikangas KR, Moore TM, Burstein M, Behr MA, Satterthwaite TD, et al. The Philadelphia Neurodevelopmental Cohort: constructing a deep phenotyping collaborative. J Child Psychol Psychiatry. 2015;56:1356-69.

[2] Bora E, Lin A, Wood SJ, Yung AR, McGorry PD, Pantelis C. Cognitive deficits in youth with familial and clinical high risk to psychosis: a systematic review and meta-analysis. Acta Psychiatr Scand. 2014;130: $1-15$.

[3] Brewer WJ, Wood SJ, Phillips LJ, Francey SM, Pantelis C, Yung AR, et al. Generalized and specific cognitive performance in clinical high-risk cohorts: a review highlighting potential vulnerability markers for psychosis. Schizophr Bull. 2006;32:538-55.

[4] Deater-Deckard K, Mullineaux PY, Beekman C, Petrill SA, Schatschneider C, Thompson LA. Conduct problems, IQ, and household chaos: a longitudinal multi-informant study. J Child Psychol Psychiatry. 2009;50: $1301-8$.

[5] Dionne G, Tremblay R, Boivin M, Laplante D, Pérusse D. Physical aggression and expressive vocabulary in 19-month-old twins. Dev Psychol. 2003;39:261.

[6] Seguin JR, Parent S, Tremblay RE, Zelazo PD. Different neurocognitive functions regulating physical aggression and hyperactivity in early childhood. J Child Psychol Psychiatry. 2009;50:679-87.

[7] Gur RE, Moore TM, Calkins ME, Ruparel K, Gur RC. Face processing measures of social cognition: a dimensional approach to developmental psychopathology. Biol Psychiatry. 2017;2:502-9.

[8] Lundy SM, Silva GE, Kaemingk KL, Goodwin JL, Quan SF. Cognitive functioning and academic performance in elementary school children with anxious/depressed and withdrawn symptoms. Open Pediatr Med J. 2010;4:1-9.

[9] Wesseldijk LW, Fedko IO, Bartels M, Nivard MG, van Beijsterveldt CE, Boomsma DI, et al. Psychopathology in 7-year-old children: Differences in maternal and paternal ratings and the genetic epidemiology. Am J Med Genet B Neuropsychiatr Genet. 2017;174:251-60.

[10] Polderman TJ, Benyamin B, de Leeuw CA, Sullivan PF, van Bochoven A, Visscher PM, et al. Meta-analysis of the heritability of human traits based on fifty years of twin studies. Nat Genet. 2015;47:702-9.

[11] Polanczyk G, Moffitt TE, Arseneault L, Cannon M, Ambler A, Keefe RS, et al. Etiological and clinical features of childhood psychotic symptoms: results from a birth cohort. Arch Gen Psychiatry. 2010;67:328-38.

[12] Zavos HM, Freeman D, Haworth CM, McGuire P, Plomin R, Cardno AG, et al. Consistent etiology of severe, frequent psychotic experiences and milder, less frequent manifestations: a twin study of specific psychotic experiences in adolescence. JAMA Psychiatry. 2014;71:1049-57.

[13] Hannigan L, Walaker N, Waszczuk M, McAdams T, Eley T. Aetiological influences on stability and change in emotional and behavioural problems across development: a systematic review. Psychopathol Rev. 2017;4:pr. 038315.

[14] Wichers M, Gardner C, Maes H, Lichtenstein P, Larsson H, Kendler K. Genetic innovation and stability in externalizing problem behavior across development: a multi-informant twin study. Behav Genet. 2013;43: 191-201.

[15] Huizink AC, Van Den Berg MP, van der Ende J, Verhulst FC. Longitudinal genetic analysis of internalizing and externalizing problem behavior in adopted biologically related and unrelated sibling pairs. Twin Res Human Genet. 2007;10:55-65.

[16] Ormel J, Oldehinkel AJ, Ferdinand RF, Hartman CA, De Winter AF, Veenstra R, et al. Internalizing and externalizing problems in adolescence: general and dimension-specific effects of familial loadings and preadolescent temperament traits. Psychol Med. 2005;35:1825-35.

[17] Gregory AM, Eley TC. The genetic basis of child and adolescent anxiety. Anxiety Disord Child Adolesc. 2011:161-78.

[18] Thapar A, McGuffin P. Are anxiety symptoms in childhood heritable? J Child Psychol Psychiatry. 1995;36:439-47.

[19] Rice F, Harold G, Thapar A. The genetic aetiology of childhood depression: a review. J Child Psychol Psychiatry. 2002;43:65-79.

[20] Birmaher B, Ryan ND, Williamson DE, Brent DA, Kaufman J, Dahl RE, et al. Childhood and adolescent depression: a review of the past 10 years. Part I. J Am Acad Child Adolesc Psychiatry. 1996;35:1427-39.

[21] Nivard MG, Dolan CV, Kendler KS, Kan KJ, Willemsen G, van Beijsterveldt $\mathrm{CE}$, et al. Stability in symptoms of anxiety and depression as a function of genotype and environment: a longitudinal twin study from ages 3 to 63 years. Psychol Med. 2015;45:1039-49.

[22] Haworth CM, Wright MJ, Luciano M, Martin NG, de Geus EJ, van Beijsterveldt CE, et al. The heritability of general cognitive ability increases linearly from childhood to young adulthood. Mol Psychiatry. 2010;15: $1112-20$.

[23] Mollon J, Knowles EEM, Mathias SR, Gur R, Peralta JM, Weiner DJ, et al. Genetic influence on cognitive development between childhood and adulthood. Mol Psychiatry. 2021;26(2):656-65.

[24] Jacobs N, Rijsdijk F, Derom C, Danckaerts M, Thiery E, Derom R, et al. Child psychopathology and lower cognitive ability: a general population twin study of the causes of association. Mol Psychiatry. 2002;7:368-74.

[25] Harden KP, Engelhardt LE, Mann FD, Patterson MW, Grotzinger AD, Savicki SL, et al. Genetic associations between executive functions and a general factor of psychopathology. J Am Acad Child Adolesc Psychiatry. 2020;59:749-58.

[26] Kuntsi J, Eley TC, Taylor A, Hughes C, Asherson P, Caspi A, et al. Cooccurrence of ADHD and low IQ has genetic origins. Am J Med Genet B Neuropsychiatr Genet. 2004;124B:41-7.

[27] Bidwell LC, Willcutt EG, Defries JC, Pennington BF. Testing for neuropsychological endophenotypes in siblings discordant for attention-deficit/ hyperactivity disorder. Biol Psychiatry. 2007;62:991-8.

[28] Doyle AE, Biederman J, Seidman LJ, Reske-Nielsen JJ, Faraone SV. Neuropsychological functioning in relatives of girls with and without ADHD. Psychol Med. 2005;35:1121-32.

[29] Wang Z, Deater-Deckard K, Petrill SA, Thompson LA. Externalizing problems, attention regulation, and household chaos: a longitudinal behavioral genetic study. Dev Psychopathol. 2012;24:755-69.

[30] Demontis D, Walters RK, Martin J, Mattheisen M, Als TD, Agerbo E, et al. Discovery of the first genome-wide significant risk loci for attention deficit/hyperactivity disorder. Nat Genet. 2019;51:63-75.

[31] O'Connell KS, Shadrin A, Smeland OB, Bahrami S, Frei O, Bettella F, et al. Identification of genetic loci shared between attention-deficit/ hyperactivity disorder, intelligence, and educational attainment. Biol Psychiatry. 2020;87(12):1052-62.

[32] Savage JE, Jansen PR, Stringer S, Watanabe K, Bryois J, de Leeuw CA, et al. Genome-wide association meta-analysis in 269,867 individuals identifies new genetic and functional links to intelligence. Nat Genet. 2018;50:912-9.

[33] Liu C-Y, Li Y, Viding E, Asherson P, Pingault J-B. The developmental course of inattention symptoms predicts academic achievement due to shared genetic aetiology: a longitudinal twin study. Eur Child Adolesc Psychiatry. 2019;28(3):367-75.

[34] Johnson W, McGue M, Iacono WG. Disruptive behavior and school grades: genetic and environmental relations in 11-year-olds. J Edu Psychol. 2005;97(3):391-405.

[35] Donati G, Dumontheil I, Meaburn EL. Genome-wide association study of latent cognitive measures in adolescence: genetic overlap with intelligence and education. Mind Brain Edu. 2019;13:224-33.

[36] Glahn DC, Kent JW Jr, Sprooten E, Diego VP, Winkler AM, Curran JE, et al. Genetic basis of neurocognitive decline and reduced white-matter integrity in normal human brain aging. PNAS. 2013;110:19006-11.

[37] Blangero J. Statistical genetic approaches to human adaptability. Hum Biol. 1993;65:5.

[38] Almasy L, Towne B, Peterson C, Blangero J. Detecting genotypex age interaction. Genet Epidemiol. 200;21:S819-S8192624. 
[40] Moore TM, Calkins ME, Satterthwaite TD, Roalf DR, Rosen AFG, Gur RC, et al. Development of a computerized adaptive screening tool for overall psychopathology ("p"). J Psychiatr Res. 2019;116:26-33.

[41] Knowles EEM, Mathias SR, Pearlson GD, Barrett J, Mollon J, Denbow D, et al. Clinical correlates of subsyndromal depression in African American individuals with psychosis: the relationship with positive symptoms and comorbid substance dependence. Schizophr Res. 2019;206:333-46.

[42] Chen FF, West SG, Sousa KH. A comparison of bifactor and second-order models of quality of life. Multivariate Behav Res. 2006;41:189-225.

[43] Reise SP, Moore TM, Haviland MG. Bifactor models and rotations: exploring the extent to which multidimensional data yield univocal scale scores. J Personality Assess. 2010;92:544-59.

[44] Reise SP. Invited paper: the rediscovery of bifactor measurement models. Multivariate Behav Res. 2012;47:667-96.

[45] Gur RC, Richard J, Hughett P, Calkins ME, Macy L, Bilker WB, et al. A cognitive neuroscience-based computerized battery for efficient measurement of individual differences: standardization and initial construct validation. J Neurosci Methods. 2010;187:254-62.

[46] Moore TM, Reise SP, Gur RE, Hakonarson H, Gur RC. Psychometric properties of the Penn computerized neurocognitive battery. Neuropsychology. 2015;29:235.

[47] Gur RC, Ragland JD, Moberg PJ, Turner TH, Bilker WB, Kohler C, et al. Computerized neurocognitive scanning: I. Methodology and validation in healthy people. Neuropsychopharmacology. 2001;25:766-76.

[48] White IR, Royston P, Wood AM. Multiple imputation using chained equations: issues and guidance for practice. Stat Med. 2011;30:377-99.

[49] van Buuren Sv, Groothuis-Oudshoorn K. mice: multivariate imputation by chained equations in R. J Stat Softw. 2010;45(3):1-68.

[50] Satterthwaite TD, Connolly JJ, Ruparel K, Calkins ME, Jackson C, Elliott MA, et al. The Philadelphia Neurodevelopmental Cohort: a publicly available resource for the study of normal and abnormal brain development in youth. Neuroimage. 2016;124:1115-9.

[51] Kaufman J, Birmaher B, Brent D, Rao U, Flynn C, Moreci P, et al. Schedule for affective disorders and schizophrenia for school-age children-present and lifetime version (K-SADS-PL): initial reliability and validity data. J Am Acad Child Adolesc Psychiatry. 1997;36:980-8.

[52] Muthén, LK, \& Muthén, BO. Mplus. Statistical analysis with latent variables. User's guide. 2009;7.

[53] Germine L, Robinson E, Smoller J, Calkins M, Moore T, Hakonarson H, et al. Association between polygenic risk for schizophrenia, neurocognition and social cognition across development. Transl Psychiatry. 2016;6:e924.

[54] Chang CC, Chow CC, Tellier LC, Vattikuti S, Purcell SM, Lee JJ. Secondgeneration PLINK: rising to the challenge of larger and richer datasets. Gigascience. 2015;4:7.

[55] Han L, Abney M. Using identity by descent estimation with dense genotype data to detect positive selection. Eur J Hum Genet. 2013;21:205-11.

[56] R Development Core Team. R: a language and environment for statistical computing. Vienna, Austria: R Foundation for Statistical Computing; 2008.

[57] Blangero J, Goring HH, Kent JW Jr, Williams JT, Peterson CP, Almasy L, et al. Quantitative trait nucleotide analysis using Bayesian model selection. Human Biol. 2005;77:541-59.

[58] Almasy L, Blangero J. Variance component methods for analysis of complex phenotypes. Cold Spring Harb Protoc. 2010;2010:pdb.top77.

[59] Almasy L, Blangero J. Multipoint quantitative-trait linkage analysis in general pedigrees. Am J Hum Genet. 1998;62:1198-211.

[60] Speed D, Hemani G, Johnson MR, Balding DJ. Improved heritability estimation from genome-wide SNPs. Am J Hum Genet. 2012;91:1011-21.

[61] Benjamini Y, Yekutieli D. The control of the false discovery rate in multiple testing under dependency. Ann Stat. 2001:1165-88.

[62] Sieradzka D, Power RA, Freeman D, Cardno AG, Dudbridge F, Ronald A. Heritability of individual psychotic experiences captured by common genetic variants in a community sample of adolescents. Behav Genet. 2015;45:493-502.

[63] Ripke S, O'Dushlaine C, Chambert K, Moran JL, Kähler AK, Akterin S, et al. Genome-wide association analysis identifies 13 new risk loci for schizophrenia. Nat Genet. 2013;45:1150.

[64] Zammit S, Hamshere M, Dwyer S, Georgiva L, Timpson N, Moskvina V, et al. A population-based study of genetic variation and psychotic experiences in adolescents. Schizophr Bull. 2014;40:1254-62.
[65] Calkins ME, Moore TM, Merikangas KR, Burstein M, Satterthwaite TD, Bilker WB, et al. The psychosis spectrum in a young US community sample: findings from the Philadelphia Neurodevelopmental Cohort. World Psychiatry. 2014;13:296-305.

[66] Häfner H, Maurer K, Löffler W, Riecher-Rössler A. The influence of age and sex on the onset and early course of schizophrenia. Br J Psychiatry. 1993;162:80-6.

[67] Kessler RC, Berglund P, Demler O, Jin R, Merikangas KR, Walters EE. Lifetime prevalence and age-of-onset distributions of DSM-IV disorders in the National Comorbidity Survey Replication. Arch Gen Psychiatry. 2005;62:593-602.

[68] Pappa I, Fedko IO, Mileva-Seitz VR, Hottenga JJ, Bakermans-Kranenburg MJ, Bartels M, et al. Single nucleotide polymorphism heritability of behavior problems in childhood: genome-wide complex trait analysis. J Am Acad Child Adolesc Psychiatry. 2015;54:737-44.

[69] Trzaskowski M, Dale PS, Plomin R. No genetic influence for childhood behavior problems from DNA analysis. J Am Acad Child Adolesc Psychiatry. 2013;52:1048-56 e3.

[70] Zaitlen N, Kraft P, Patterson N, Pasaniuc B, Bhatia G, Pollack S, et al. Using extended genealogy to estimate components of heritability for 23 quantitative and dichotomous traits. PLoS Genet. 2013;9:e1003520.

[71] Knowles EE, Carless MA, de Almeida MA, Curran JE, McKay DR, Sprooten E, et al. Genome-wide significant localization for working and spatial memory: Identifying genes for psychosis using models of cognition. Am J Med Genet B Neuropsychiatr Genet. 2014;165B:84-95.

[72] Lichtenstein P, Annas P. Heritability and prevalence of specific fears and phobias in childhood. J Child Psychol Psychiatry. 2000;41:927-37.

[73] Kendler KS, Gardner CO, Annas P, Neale MC, Eaves LJ, Lichtenstein P. A longitudinal twin study of fears from middle childhood to early adulthood: evidence for a developmentally dynamic genome. Arch Gen Psychiatry. 2008;65:421-9.

[74] Micalizzi L, Brick LA, Marraccini ME, Benca-Bachman CE, Palmer RHC, Knopik VS. Single nucleotide polymorphism heritability and differential patterns of genetic overlap between inattention and four neurocognitive factors in youth. Dev Psychopathol. 2020:1-11.

[75] Huguet G, Schramm C, Douard E, Tamer P, Main A, Monin P, et al. Genome-wide analysis of gene dosage in 24,092 individuals estimates that 10,000 genes modulate cognitive ability. Mol. Psychiatry. 2021.

[76] Kendall KM, Bracher-Smith M, Fitzpatrick H, Lynham A, Rees E, EscottPrice V, et al. Cognitive performance and functional outcomes of carriers of pathogenic copy number variants: analysis of the UK Biobank. Br J Psychiatry. 2019;214:297-304.

[77] Harich B, van der Voet M, Klein M, Cizek P, Fenckova M, Schenck A, et al. From rare copy number variants to biological processes in ADHD. Am J Psychiatry. 2020;177:855-66.

[78] Martin J, O'Donovan MC, Thapar A, Langley K, Williams N. The relative contribution of common and rare genetic variants to ADHD. Transl Psychiatry. 2015;5:e506.

[79] Stergiakouli E, Hamshere M, Holmans P, Langley K, Zaharieva I, Hawi Z, et al. Investigating the contribution of common genetic variants to the risk and pathogenesis of ADHD. Am J Psychiatry. 2012;169:186-94.

[80] Glahn DC, Knowles EE, McKay DR, Sprooten E, Raventós H, Blangero J, et al. Arguments for the sake of endophenotypes: examining common misconceptions about the use of endophenotypes in psychiatric genetics. Am J Med Genet B Neuropsychiatr Genet. 2014;165:122-30.

[81] Gottesman II, Gould TD. The endophenotype concept in psychiatry: etymology and strategic intentions. Am J Psychiatry. 2003;160:636-45.

[82] Kan KJ, Dolan CV, Nivard MG, Middeldorp CM, van Beijsterveldt CE, Willemsen $\mathrm{G}$, et al. Genetic and environmental stability in attention problems across the lifespan: evidence from the Netherlands twin register. J Am Acad Child Adolesc Psychiatry. 2013;52:12-25.

[83] Miettunen J, Murray GK, Jones PB, Maki P, Ebeling H, Taanila A, et al. Longitudinal associations between childhood and adulthood externalizing and internalizing psychopathology and adolescent substance use. Psychol Med. 2014;44:1727-38.

[84] Scourfield J, Van den Bree M, Martin N, McGuffin P. Conduct problems in children and adolescents: a twin study. Arch Gen Psychiatry. 2004;61: 489-96. 